\title{
Stanozolol administration combined with exercise leads to decreased telomerase activity possibly associated with liver aging
}

\author{
EREN OZCAGLI $^{1 *}$, MEHTAP KARA $^{1^{*}}$, TUGBA KOTIL $^{2}$, \\ PERSEFONI FRAGKIADAKI ${ }^{3}$, MANOLIS N. TZATZARAKIS ${ }^{3}$, CHRISTINA TSITSIMPIKOU $^{4}$, \\ POLYCHRONIS D. STIVAKTAKIS ${ }^{3}$, DIMITRIOS TSOUKALAS ${ }^{3}$, DEMETRIOS A. SPANDIDOS ${ }^{5}$, \\ ARISTIDES M. TSATSAKIS ${ }^{3}$ and BUKET ALPERTUNGA ${ }^{1}$
}

\begin{abstract}
${ }^{1}$ Department of Pharmaceutical Toxicology, Faculty of Pharmacy, and ${ }^{2}$ Department of Histology and Embryology, Faculty of Medicine, Istanbul University, Istanbul 34116, Turkey; ${ }^{3}$ Laboratory of Forensic Sciences and Toxicology, Medical School, University of Crete, 71003 Heraklion; ${ }^{4}$ General Chemical State Laboratory of Greece, 11521 Athens;

${ }^{5}$ Laboratory of Clinical Virology, Medical School, University of Crete, 71003 Heraklion, Greece
\end{abstract}

Received February 28, 2018; Accepted April 11, 2018

DOI: $10.3892 / \mathrm{ijmm} .2018 .3644$

\begin{abstract}
Anabolic agents are doping substances which are commonly used in sports. Stanozolol, a $17 \alpha$-alkylated derivative of testosterone, has a widespread use among athletes and bodybuilders. Several medical and behavioral adverse effects are associated with anabolic androgenic steroids (AAS) abuse, while the liver remains the most well recognized target organ. In the present study, the hepatic effects of stanozolol administration in rats at high doses resembling those used for doping purposes were investigated, in the presence or absence of exercise. Stanozolol and its metabolites, $16-\beta$-hydroxystanozolol and 3'-hydroxystanozolol, were detected in rat livers using liquid chromatography-mass spectrometry (LC-MS). Telomerase activity, which is involved in cellular aging and tumorigenesis, was detected by examining telomerase reverse
\end{abstract}

Correspondence to: Professor Buket Alpertunga, Department of Pharmaceutical Toxicology, Faculty of Pharmacy, Istanbul University, Beyazit, Istanbul 34116, Turkey

E-mail: tunga@istanbul.edu.tr

Professor Aristides M. Tsatsakis, Laboratory of Forensic Sciences and Toxicology, Medical School, University of Crete, P.O. Box 1393, 71003 Heraklion, Greece

E-mail: toxlab.uoc@gmail.com

*Contributed equally

Abbreviations: AAS, anabolic androgenic steroid; TERT, telomerase reverse transcriptase; TERC, telomerase RNA component; WADA, World Anti-doping Agency; HCC, hepatocellular carcinoma; PG, propylene glycol; IS, internal standard; APCI, atmospheric pressure chemical ionization; PBMCs, peripheral blood mononuclear cells

Key words: stanozolol, phosphatase and tensin homolog, telomerase reverse transcriptase, telomerase activity, 16 - $\beta$-hydroxystanozolol, 3'-hydroxystanozolol transcriptase (TERT) and phosphatase and tensin homolog (PTEN) expression levels in the livers of stanozolol-treated rats. Stanozolol induced telomerase activity at the molecular level in the liver tissue of rats and exercise reversed this induction, reflecting possible premature liver tissue aging. PTEN gene expression in the rat livers was practically unaffected either by exercise or by stanozolol administration.

\section{Introduction}

Stanozolol is a performance-enhancing anabolic androgenic steroid (AAS). Among all AASs, stanozolol is one of the most frequently abused steroids by professional athletes and young adults in order to ameliorate physical appearance and performance. Stanozolol is a $17 \alpha$-alkylated derivative of testosterone with anabolic and high androgenic properties $(1,2)$ and its use is prohibited in sports by the World Anti-doping Agency (WADA) (3).

In the past, AASs were used only by elite athletes and bodybuilders for doping purposes. However, nowadays even young adults are abusing AASs at supraphysiological doses in order to improve physical appearance $(4,5)$. Stanozolol has been reported to be one of the most commonly abused AAS (6) and it is responsible for several medical and behavioral adverse effects, being a recognized risk factor for liver diseases, both in experimental animals and in human beings (7-13). Stanozolol is extensively biotransformed by enzymatic pathways in the liver. The major metabolites of stanozolol have been reported to be 3'-hydroxystanozolol, 4- $\beta$-hydroxystanozolol and 16 - $\beta$-hydroxystanozolol $(14,15)$. In general, AASs exert their effects through several different mechanisms, such as by modulating androgen receptor expression (16). Liver-related adverse effects are more commonly associated with the $17 \alpha$-alkyl derivatives of AASs and have been reported not to be related with the route of administration. However, the exact mechanisms are not yet fully understood (17).

Telomeres are heterochromatin nucleoprotein complexes on the chromosome ends involved in a number of basic 
biological functions (Fig. 1). It is known that telomeres play a key role in the formation and progression of up to $90 \%$ of malignancies. Telomerase activity plays a key role in cellular aging and tumorigenesis (18). An increased telomerase activity is detected in the majority of human cancers (19). Telomerase is a ribonucleoprotein responsible for maintaining telomere length. The core of telomerase has two components: Catalytic telomerase reverse transcriptase (TERT) and telomerase RNA component (TERC) (Fig. 2).

The TERT mRNA expression level has been studied as a biomarker, as it has been demonstrated to be the rate-limiting determinant of telomerase activity in various malignancies (20). The phosphatase and tensin homolog protein (PTEN) gene encodes a tumor suppressor protein with phosphatase activity. It has been reported that PTEN has a loss of heterozygosity frequency incidence in human hepatocellular carcinoma (HCC) of up to $33 \%$ (21). PTEN is involved in the downregulation of telomerase activity via TERT activity regulation (22). PTEN is a negative regulator protein of the phosphoinositide 3-kinase/AKT signaling pathway of the cell survival regulatory mechanism and induces cellular apoptosis (23). PTEN prevents the activation of AKT via the de-phosphorilation of phosphatidylinositol (3,4,5)-trisphosphate (PIP3) to phosphatidylinositol 4,5-bisphosphate (PIP2). The suppression of PTEN is associated with oncogenic activity in the cell (24).

The aim of this study was to investigate, for the first time, at least to the best of our knowledge, the role of telomerase in stanozolol-induced hepatotoxicity by investigating the correlation between telomerase activity and PTEN-TERT gene expression levels. The bioaccumulation of stanozolol and its two major metabolites (3'-hydroxystanozolol and 16 - $\beta$-hydroxystanozolol) in the liver tissue was also examined, as well as its association with telomerase activity.

\section{Materials and methods}

Animal experiments. A total of 34 male Sprague-Dawley rats, 8 weeks old, were obtained and housed in the laboratory animal house facilities of the Department of Laboratory Animal Sciences, Institute of Experimental Medicine, Istanbul University (Istanbul, Turkey), in accordance with the Ethics Committee on Animal Experimentation of Istanbul University, HADYEK (approval no. 2013/100). The rats were divided into 5 groups as follows: i) The control (C) group; ii) the propylene treatment (PG) group; iii) the stanozolol treatment (ST) group; iv) the propylene treatment and exercise (PGE) group; and v) the stanozolol treatment and exercise (STE) group. The animals were housed as 4 animals per one metal cage and kept in a 12-h dark/light cycle at a temperature of $20-23^{\circ} \mathrm{C}$. The number of rats per experimental group, rat care, handling and employed experimental procedures were in accordance with the guidelines of HADYEK. The weight of the rats upon purchase was recorded and used for dose adjustments (Table I). The humane endpoints defined in our study were pain, distress, abnormal posture and seizures in accordance with the OECD Guidance Document (25). No animals exhibited clinical signs of humane endpoints that justified their sacrifice prior to the end of the experiment. The experimental design of the study is presented in Table II.

Swimming was selected as a model of exercise $(26,27)$ and began 1 week prior to the treatment scheme in order for the

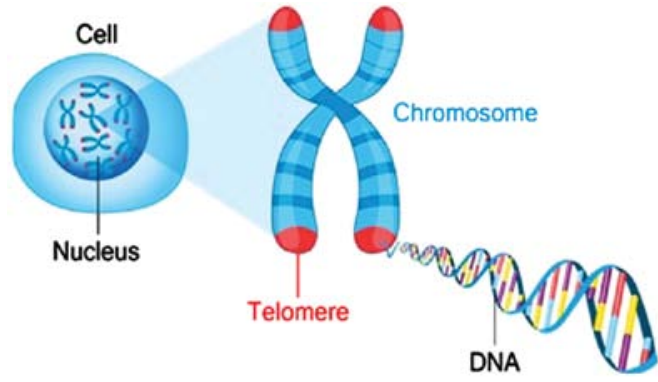

Figure 1. Telomeres are protective caps of chromosomes (59) (adapted with permission from Shutterstock).

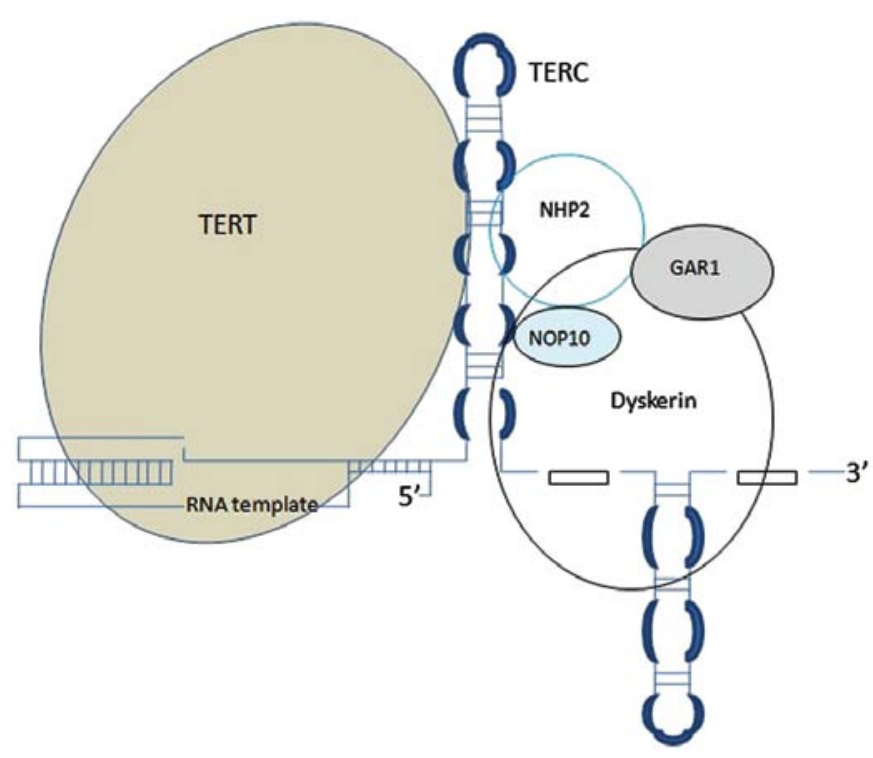

Figure 2. Telomerase adds telomeric repeats (TTAGGG) to the 3'-hydroxyl end of the leading strand of the telomere. The RNA component serves as the template for nucleotide addition. This is the Telomerase Complex and it consists of the reverse transcriptase component (TERT), the RNA component (TERC), the protein Dyskerin and other associated proteins (NHP2, NOP10 and GAR1).

animals to adapt. The rats were subjected to swimming in a rectangular polyethylene tank $(120-\mathrm{cm}$-long x 50 -cm-deep x 43 -cm-wide) filled with water at $29 \pm 1^{\circ} \mathrm{C}$. During the experiments, for $20 \mathrm{~min} /$ day, 5 days/week, the rats were subjected to swimming following an adaptation period of 1 week. The animals were adapted to the process by swimming in water for 5 min during the first 2 days, and swimming time was then gradually increased to $5 \mathrm{~min}$ per day up to a final duration of 20 min on day 5 .

Propylene glycol (PG) (Tekkim, Istanbul, Turkey) was used as a vehicle for stanozolol (Sigma, Schnelldorf, Germany). PG is known to be a good vehicle for in vivo experimental studies $(28,29)$. However, it has been reported that high concentrations of PG can induce DNA damage in eukaryotic cells and mouse oocytes $(30,31)$. Subcutaneous administration was selected and the doses were selected in accordance with previous studies (32-34). The exposed groups received a single dose of PG $(1 \mathrm{ml} / \mathrm{kg})$ and ST $(5 \mathrm{ml} / \mathrm{kg})$ subcutaneously for 5 days per week.

After 28 days of treatment, the animals underwent light anesthesia using a percentage of $1.9 \%$ diethyl-ether in an 
Table I. Weight of the rats upon purchase.

\begin{tabular}{|c|c|}
\hline Number of rats & Weight of rats upon purchase $(\mathrm{g})$ \\
\hline \multicolumn{2}{|l|}{ Control } \\
\hline 1 & 259 \\
\hline 2 & 268 \\
\hline 3 & 271 \\
\hline 4 & 264 \\
\hline 5 & 282 \\
\hline \multicolumn{2}{|c|}{ Propylene glycol } \\
\hline 1 & 255 \\
\hline 2 & 276 \\
\hline 3 & 273 \\
\hline 4 & 261 \\
\hline 5 & 272 \\
\hline \multicolumn{2}{|c|}{ Propylene glycol and exercise } \\
\hline 1 & 262 \\
\hline 2 & 276 \\
\hline 3 & 284 \\
\hline 4 & 264 \\
\hline 5 & 278 \\
\hline 6 & 263 \\
\hline 7 & 260 \\
\hline 8 & 277 \\
\hline \multicolumn{2}{|l|}{ Steroid group } \\
\hline 1 & 280 \\
\hline 2 & 265 \\
\hline 3 & 275 \\
\hline 4 & 272 \\
\hline 5 & 277 \\
\hline 6 & 272 \\
\hline 7 & 263 \\
\hline 8 & 290 \\
\hline \multicolumn{2}{|c|}{ Steroid and exercise group } \\
\hline 1 & 275 \\
\hline 2 & 277 \\
\hline 3 & 290 \\
\hline 4 & 263 \\
\hline 5 & 280 \\
\hline 6 & 285 \\
\hline 7 & 279 \\
\hline 8 & 273 \\
\hline
\end{tabular}

anesthesia chamber and euthanized by cervical dislocation carried out properly trained personnel. Liver tissue samples were collected and divided into 2 sections. One section was immediately frozen in liquid nitrogen and stored at $-80^{\circ} \mathrm{C}$, and the other was fixed with $10 \%$ buffered formalin and embedded paraffin for histochemical analysis.

Liquid chromatography-mass spectrometry (LC-MS) analysis. Standards of stanozolol, 3'-hydroxystanozolol and 16 - $\beta$-hydroxystanozolol at concentrations of $0,0.1,0.25,0.5$ and 1 ppm were prepared from 20 ppm standard stock solutions. Turinabol (LGC, Leeds, UK) was used as an internal standard (IS) with target ions $\mathrm{m} / \mathrm{z} 317.25$ and $\mathrm{m} / \mathrm{z} 335.25$. Calibration curves were obtained by measuring the peak of target ions areas ratio to IS as follows: For stanozolol m/z 370.4, 352.3 and 329.35 , for 3'-hydroxystanozolol $\mathrm{m} / \mathrm{z}$ 386.4, 345.35, for $16-\beta$-hydroxystanozolol $\mathrm{m} / \mathrm{z}$ 386.4, 366.3 and 345.35 for IS turinabol (Table III) (the $\mathrm{m} / \mathrm{z}$ ion used for quantification is shown in bold font). The liver samples of the untreated animals that yielded negative results $(<\mathrm{LOD})$ during screening were used as blank matrices for the preparation of spiked standard samples at various concentrations $(0,1,2,5$ and $10 \mathrm{ng} / \mathrm{mg})$. The spiked samples were used for the preparation of spiked curves and furthermore for the determination of stanozolol, 3 '-hydroxystanozolol and 16- $\beta$-hydroxystanozolol levels in the liver samples.

Approximately $0.1 \mathrm{~g}$ of liver sample from each animal were mechanical homogenized at high speed for 2 min with $1.0 \mathrm{ml}$ of water. The homogenates were strongly vortexed and then incubated in an ultrasonic bath for $10 \mathrm{~min}$. The addition of $1.5 \mathrm{ml}$ of ethyl acetate followed and the extraction of the analytes was performed for $10 \mathrm{~min}$. The samples were centrifuged at $1,820 \mathrm{x} \mathrm{g}$ for $2 \mathrm{~min}$ at $4^{\circ} \mathrm{C}$. The supernatants were transferred to an empty tube and evaporated to dryness under nitrogen at $30^{\circ} \mathrm{C}$. Following evaporation, $100 \mu 1$ acetonitrile were added and strongly vortexed. The supernatants were transferred to vials and $10 \mu \mathrm{l}$ of these were injected to the LC-MS system for analysis.

The LC-MS system consists of a binary LC pump (Shimadzu Prominence, Kyoto Japan), a vacuum degasser, an autosampler and a column oven. A gradient of $0.1 \%$ formic acid in water (solvent A) and acetonitrile (solvent B) were selected as the mobile phase. The separation of analytes was achieved on a Discovery C18 HPLC column $(250 \times 4.6 \mathrm{~mm}, 5 \mu \mathrm{m})$ thermostated at $30^{\circ} \mathrm{C}$. A mass spectrometer (LCMS-2010 EV; Shimadzu Prominence), coupled with an atmospheric pressure chemical ionization (APCI) interface and a single quadrupole mass filter was used in a selected ion monitoring (SIM) positive mode. The interface, CDL and heat block temperatures were 400,200 and $200^{\circ} \mathrm{C}$, respectively. The detector voltage was $1.5 \mathrm{kV}$, the nebulizing gas flow was $2.5 \mathrm{l} / \mathrm{min}$ and the drying gas was set at $0.02 \mathrm{MPa}$.

Telomerase activity assay. The determination of telomerase activity in rat liver tissue samples was performed quantitatively using the teloTAGGG telomerase PCR ELISA PLUS kit (Roche Diagnostic GmbH, Mannheim, Germany). The kit protocol was followed for telomerase activity assessment as previously described $(35,36)$.

Gene expression assessment. RNA isolation was performed from paraffin-embedded rat liver tissue sections using the High Pure FFPET RNA isolation (Roche Diagnostic GmbH), according to the manufacturer's instructions. A fixed amount of RNA from each sample was used for cDNA synthesis. cDNA was prepared using the Transcriptor First Strand cDNA Synthesis kit (Roche Diagnostic $\mathrm{GmbH}$ ) according to the manufacturer's instructions. The gene expression levels of TERT and PTEN were analyzed by quantitative (real-time) polymerase chain reaction (qPCR) using Light Cycler 480 machine (Roche 
Table II. Experimental design of the study.

\begin{tabular}{|c|c|c|c|}
\hline Groups & No. of rats & Subcutaneous injections & Exercise \\
\hline Control & 5 & No injection & No exercise \\
\hline Propylene glycol treatment & 5 & $1 \mathrm{ml} / \mathrm{kg}$ propylene glycol per day & No exercise \\
\hline Stanozolol treatment & 8 & $5 \mathrm{mg} / \mathrm{kg}$ stanozolol per day & No exercise \\
\hline Propylene glycol treatment and exercise & 8 & $1 \mathrm{ml} / \mathrm{kg}$ propylene glycol per day & $\begin{array}{l}\text { Swimming: } 20 \mathrm{~min} / \text { day, } \\
5 \text { days/week }\end{array}$ \\
\hline Stanozolol treatment and exercise & 8 & $5 \mathrm{mg} / \mathrm{kg}$ stanozolol per day & $\begin{array}{c}\text { Swimming: } 20 \mathrm{~min} / \text { day, } \\
5 \text { days/week }\end{array}$ \\
\hline
\end{tabular}

Table III. LC-MS analysis parameters.

\begin{tabular}{|c|c|c|c|c|c|}
\hline Agent & $\mathrm{Rt}$ & $\mathrm{m} / \mathrm{z}$ target & $\mathrm{m} / \mathrm{z}$ & $\mathrm{m} / \mathrm{z}$ & Mw \\
\hline $4 \alpha$-hydroxystanozolol & 9 & 386.4 & 345.35 & & \\
\hline $4 \beta$-hydroxystanozolol & 9.3 & 386.4 & 345.35 & & \\
\hline 3-hydroxystanozolol & 10.15 & 386.4 & 345.35 & & 344.49 \\
\hline $16-\beta$ hydroxystanozolol & 10.45 & 386.4 & 366.3 & 345.35 & 344.49 \\
\hline Stanozolol & 12.95 & 370.4 & 352.3 & 329.35 & 328.49 \\
\hline Turinabol (IS) & 13.9 & 317.25 & 335.25 & & 334.9 \\
\hline
\end{tabular}

LC-MS, liquid chromatography-mass spectrometry; IS, internal standard.

Diagnostic GmbH) with Real Time Ready Catalog Assay (Roche Diagnostic GmbH) according to the manufacturer's instructions. The primer sequences were as follows: PTEN forward, 5'-AGA ACAAGATGCTCAAAAAGGACAA-3' and reverse, 5'-TGTCAGGGTGAGCACAAGAT-3'; TERT forward, 5'-GACATGGAGAACAAGCTGTTTGC-3'; and reverse, 5'-ACAGGGAAGTTCACCACTGTC-3'; and GAPDH forward, 5'-TTCAACGGCACAGTCAAGG-3' and reverse, 5'-CTCAGCACCAGCATCACC-3'. PCR amplifications were performed according to manufacturer's instructions in triplicate. A reaction mixture without cDNA template was used as a negative control. The expression levels $\left(2^{-\Delta \Delta \mathrm{Ct}}\right)$ was calculated as described previously $(37,38)$.

Immunohistochemistry (IHC) analysis. IHC analyses were performed using the Ultra Streptavidin HRP Detection kits [BioLegend Sig-32248, Ultra Streptavidin HRP Detection kit (Multi-species, DAB)] and BioLegend Sig-32250, Ultra Streptavidin HRP Detection kit (Multi-species, AEC) (BioLegend, San Diego, CA, USA) for PTEN and TERT expression levels, respectively. The paraffin-embedded sections were mounted on Superfrost microscope slides (Menzel-Gläser, Braunschweig, Germany). After drying overnight, IHC analysis of PTEN and TERT was performed using the labeled streptavidin-biotin-peroxidase method. The slides were treated with xylene and rehydrated in increasing grades of ethanol solutions. Antigen retrieval was performed by boiling the slides for $5 \mathrm{~min} / 3$ times in citrate buffer $(0.01 \mathrm{M})$. In order to quench endogenous peroxidase activity, the tissue sections were treated with Blocking Reagent 1 for 15 min and washed with PBS. All the sections were incubated with Blocking Reagent 2 for $5 \mathrm{~min}$ at room temperature to avoid any non-specific binding. PTEN (251264) and TERT (250509) (both from Abbiotec, Aachen, Germany) polyclonal antibody incubations were performed overnight at $4^{\circ} \mathrm{C}$ with $1 / 100$ dilutions. The slides were incubated with Linking Reagent 4 and then Labeling Reagent 5 for $20 \mathrm{~min}$ at room temperature. The slides were visualized with DAB and AEC chromogens, counterstained with Mayer's hematoxylin and finally mounted. The expression levels of PTEN and TERT were evaluated under a light microscope (Olympus BX40F4; Olympus, Tokyo, Japan). TERT and PTEN IHC analyses were classified by the naked eye into 4 categories on the basis of the staining intensity as follows: 0 , no staining; +, weak staining; ++ , moderate staining; and +++ , strong staining). Analysis was performed using a one slide reader for minimizing variability due to subjective scoring.

Statistical analysis. The means \pm SD and the median were used for the expression of levels of stanozolol and its metabolites and for PTEN, TERT and percentage relative telomerase activity. Changes between two values were expressed as percentage relative changes or otherwise based on the following formula: (actual change/reference value) $* 100 \%$.

The Kolmogorov-Smirnov with Liliefors correction test was applied for examining the normality of continuous variables. Spearman's R was applied to measure bivariate correlations between two continuous variables (e.g., percentage relative telomerase activity vs. the levels of 3'-hydroxystanozolol TERT gene expression). The non-parametric Kruskal-Wallis test and parametric one-way ANOVA were applied for comparing differences in levels of stanozolol and its metabolites between 
Table IV. Concentration levels (ng/mg) of stanozolol and its metabolites in the stanozolol (ST) and stanozolol plus exercise (STE) groups.

\begin{tabular}{lcccc}
\hline Agent & $\begin{array}{c}\text { ST group } \\
(\text { means } \pm \text { SD) }\end{array}$ & $\begin{array}{c}\text { STE group } \\
(\text { means } \pm \text { SD })\end{array}$ & $\begin{array}{c}\text { Mann-Whitney } \\
(\text { P-value })\end{array}$ & \% relative change \\
\hline Stanozolol (ng/mg) & $2.98 \pm 1.01$ & $3.89 \pm 1.09$ & 0.240 & 30.5 \\
3'-hydroxystanozolol (ng/mg) & $0.34 \pm 0.06$ & $0.44 \pm 0.18$ & 0.485 & 29.4 \\
16- $\beta$-hydroxystanozolol (ng/mg) & $0.25 \pm 0.11$ & $0.32 \pm 0.15$ & 0.485 & 28.0 \\
\hline
\end{tabular}

Table V. PTEN and TERT gene expression levels $\left(2^{-\Delta \Delta C t}\right)$ and \% relative telomerase activity per group.

\begin{tabular}{|c|c|c|c|c|c|}
\hline Parameters & Groups & $\mathrm{N}$ & Mean & SD & Group comparison \\
\hline \multirow[t]{5}{*}{ PTEN gene expression $\left(2^{-\Delta \Delta C t}\right)$} & Control & 5 & 1.13 & 1.77 & \multirow{5}{*}{$\begin{array}{l}\text { Kruskal-Wallis } \\
\chi^{2}=3.643, \\
\mathrm{df}=4, \mathrm{P}=0.456\end{array}$} \\
\hline & Propylene glycol treatment & 5 & 0.37 & 0.25 & \\
\hline & Stanozolol treatment & 6 & 0.40 & 0.42 & \\
\hline & Propylene glycol treatment and exercise & 5 & 0.98 & 1.62 & \\
\hline & Stanozolol treatment and exercise & 6 & 1.13 & 0.86 & \\
\hline \multirow[t]{5}{*}{ TERT gene expression $\left(2^{-\Delta \Delta C t}\right)$} & Control & 5 & 0.40 & 0.41 & \multirow{5}{*}{$\begin{array}{l}\text { Kruskal-Wallis } \\
\chi^{2}=17.585 \\
\mathrm{df}=4, \mathrm{P}=0.001\end{array}$} \\
\hline & Propylene glycol treatment & 5 & 2.78 & 2.66 & \\
\hline & Stanozolol treatment & 6 & 7.25 & 1.40 & \\
\hline & Propylene glycol treatment and exercise & 5 & 0.81 & 0.96 & \\
\hline & Stanozolol treatment and exercise & 6 & 2.29 & 0.97 & \\
\hline \multirow[t]{5}{*}{$\%$ relative telomerase activity } & Control & 5 & 1.30 & 0.58 & \multirow{5}{*}{$\begin{array}{l}\text { ANOVA: } \\
\mathrm{F}=3.015, \mathrm{df}=4 \\
\mathrm{P}=0.040\end{array}$} \\
\hline & Propylene glycol treatment & 5 & 1.92 & 0.96 & \\
\hline & Stanozolol treatment & 6 & 2.59 & 1.30 & \\
\hline & Propylene glycol treatment and exercise & 5 & 0.76 & 0.61 & \\
\hline & Stanozolol treatment and exercise & 6 & 1.33 & 0.96 & \\
\hline
\end{tabular}

PTEN, phosphatase and tensin homolog protein, TERT, telomerase reverse transcriptase.

the study groups (control, stanozolol, PG and exercise groups). Non-parametric post hoc comparisons were assessed by using Dunn's (non-paremetric) and Tukey's HSD tests for parametric tests. IBM SPSS Statistics 21.0 software (IBM Corp., Armonk, NY, USA) was used for statistical analysis. A level of 0.05 was set for accepting or rejecting the null hypothesis (statistical significance). The sample sizes for the individual analyses differed slightly due to some missing values arose from experimental conditions.

\section{Results}

Normality tests. Tests for normality revealed that only percentage relative telomerase activity retained the null hypothesis, suggesting a normal distribution of data $(\mathrm{P}=0.137)$. All other continuous variables tested, such as TERT, PTEN and 3'-hydroxystanozolol did not follow a normal distribution $(\mathrm{P}<0.01)$ (data not shown).

Bioaccumulation of stanozolol and its metabolites in liver tissues. The results are summarized in Table IV. The levels of stanozolol and its metabolites were non-significantly higher in the STE group compared to the ST group $(\mathrm{P}>0.05)$.
Telomerase activity and gene expression assessment. The PTEN and TERT gene expression levels and percentage relative telomerase activity in the study groups are presented in Table V. A significant difference was observed for TERT gene expression in the various groups $\left(\chi^{2}=17.585, \mathrm{df}=4, \mathrm{P}<0.001\right)$. Based on the Dunn's test, exercise reduced TERT expression by $(71.0 \% ; \mathrm{P}=0.001)$ and $\mathrm{ST}$ administration increased TERT expression by $(160 \%$; $\mathrm{P}<0.001)$ compared to the $\mathrm{PG}$ group. Of note, the stanozolol-induced increase in TERT expression vs. the stanozolol group was restricted by $(68.0 \%$; $\mathrm{P}=0.042)$ in the animals subjected to exercise. A similar pattern was observed for percentage telomerase activity, as well. PTEN gene expression was practically unaffected either by exercise or stanozolol administration. It should be noted that not all values presented above are shown in Table $\mathrm{V}$ due to the large number of pairwise comparisons.

A moderate correlation between percentage relative telomerase activity and TERT gene expression levels was observed using Spearman's correlation coefficient $(r=0.424$, $\mathrm{P}=0.028$ ) (Fig. 3). The levels of 3'-hydroxystanozolol measured in the ST and STE groups tended to negatively correlate with percentage relative telomerase activity (Spearman's $\mathrm{r}=-0.566, \mathrm{P}=0.055$ ) (Fig. 4). No correlation was observed 
Table VI. Scoring results for PTEN and TERT immunohistochemical analyses.

\begin{tabular}{lcc}
\hline Groups & PTEN IHC scoring $^{\mathrm{a}}$ & TERT IHC scoring $^{\mathrm{a}}$ \\
\hline Control & + & + \\
Propylene glycol treatment & ++ & ++ \\
Stanozolol treatment & + & +++ \\
Propylene glycol treatment and exercise & + & + \\
Stanozolol treatment and exercise & ++ & ++
\end{tabular}

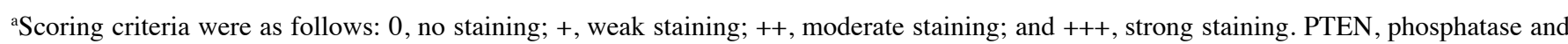
tensin homolog protein, TERT, telomerase reverse transcriptase; IHC, immunohistochemistry.

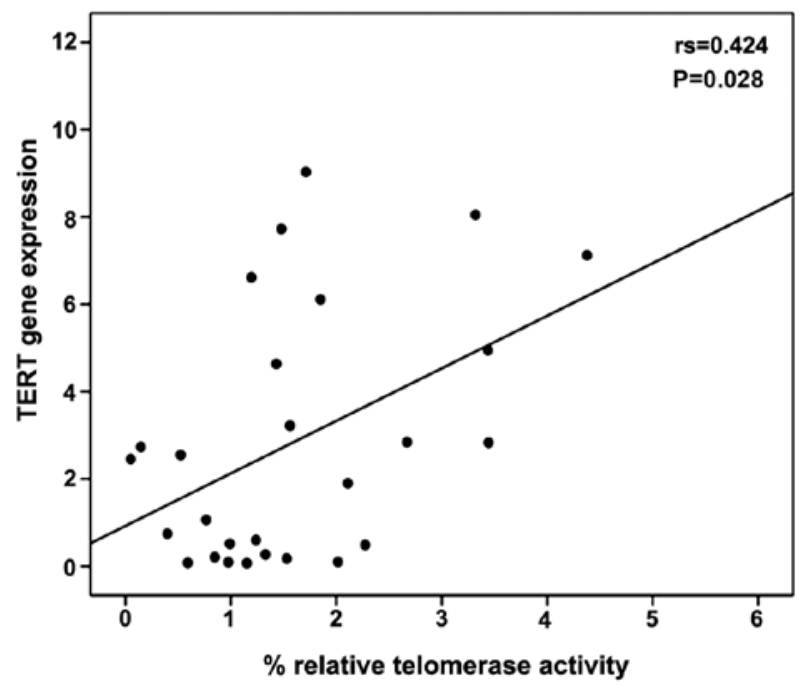

Figure 3. Scatter diagram of TERT gene expression and percentage relative telomerase activity. TERT, telomerase reverse transcriptase.

between any of the parameters monitored with stanozolol and 16- $\beta$-hydroxystanozolol (data not shown).

IHC analyses. The IHC staining images are shown in Fig. 5 and the results are summarized in Table VI. PTEN gene expression levels were observed around the vena centralis and the parenchyma. In the STE group, the staining was moderate in the hepatocytes surrounding these areas. TERT IHC analysis revealed strong staining in the ST group around the portal field, vena centralis and parenchyma, while exercise attenuated the increase in TERT gene expression (moderate staining in the STE group). Our results thus indicated that exercise exerted positive effects on PTEN gene expression, as shown in Table V.

\section{Discussion}

Stanozolol is a widely abused and most potent AAS responsible for a number of side-effects, including cardiovascular, reproductive, behavioral effects and hepatotoxicity (17). To the best of our knowledge, this is the first study to investigate stanozolol-induced molecular pathways of telomerase activity in rat liver and any relevant effect of exercise. Stanozolol induces intrahepatic structural changes with cholestasis and

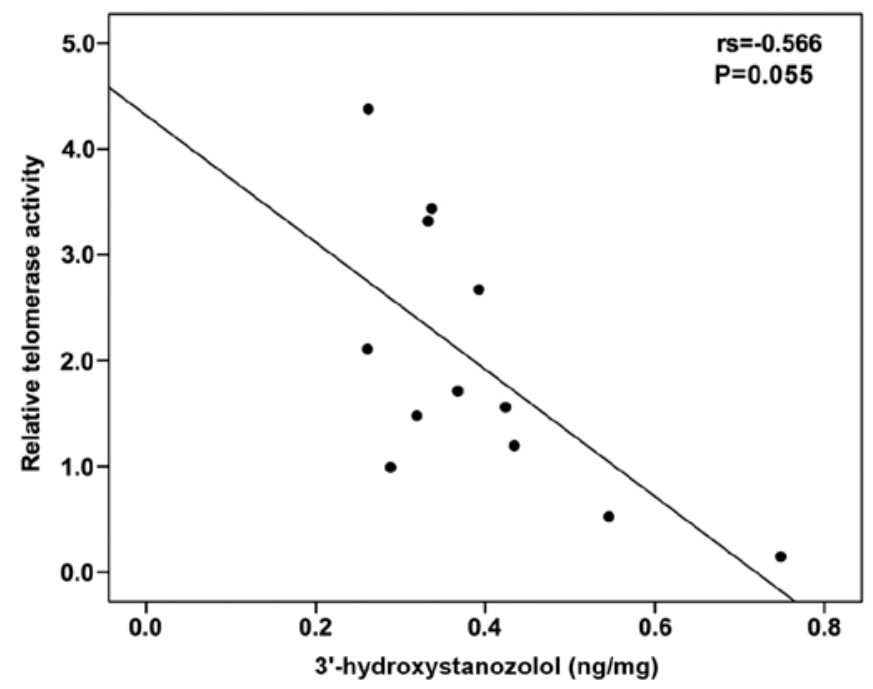

Figure 4. Scatter diagram of 3'-hydroxystanozolol and percentage relative telomerase activity.

increases the risk of HCC (37). In addition, AAS abuse in general has been found to be responsible for hepatocellular adenomas $(12,39)$. Even though the mechanisms responsible for stanozolol-induced hepatotoxicity have not yet been clearly identified, proliferative effects on liver cells may play a central role in the observed hepatotoxicity $(12,40,41)$. In our previous study, we demonstrated that stanozolol exerted DNA-damaging effects in peripheral blood lymphocytes, probably related to telomerase activity alterations (35). Although various environmental factors are known to up- and downregulate telomerase activity, the effects of exercise on telomerase activity have not yet been clearly identified (42). Telomere length and telomerase activity have been shown to be affected by several factors, including oxidative stress, psychological stress and socioeconomic status. One possible mechanism for telomere shortening is oxidative stress by oxidized DNA base products $(8-\mathrm{OHdG})$ in the guanine or protein adducts $(43,44)$. According to recent studies, an increased telomerase activity is detected in almost $90 \%$ of human cancers and in $80 \%$ of HCCs. In addition, it is well documented that the majority of healthy cells exhibit a lack of telomerase activity $(19,20,45)$. The results of this study demonstrated increased levels of percentage relative telomerase activity in the liver tissue in the ST group, in 

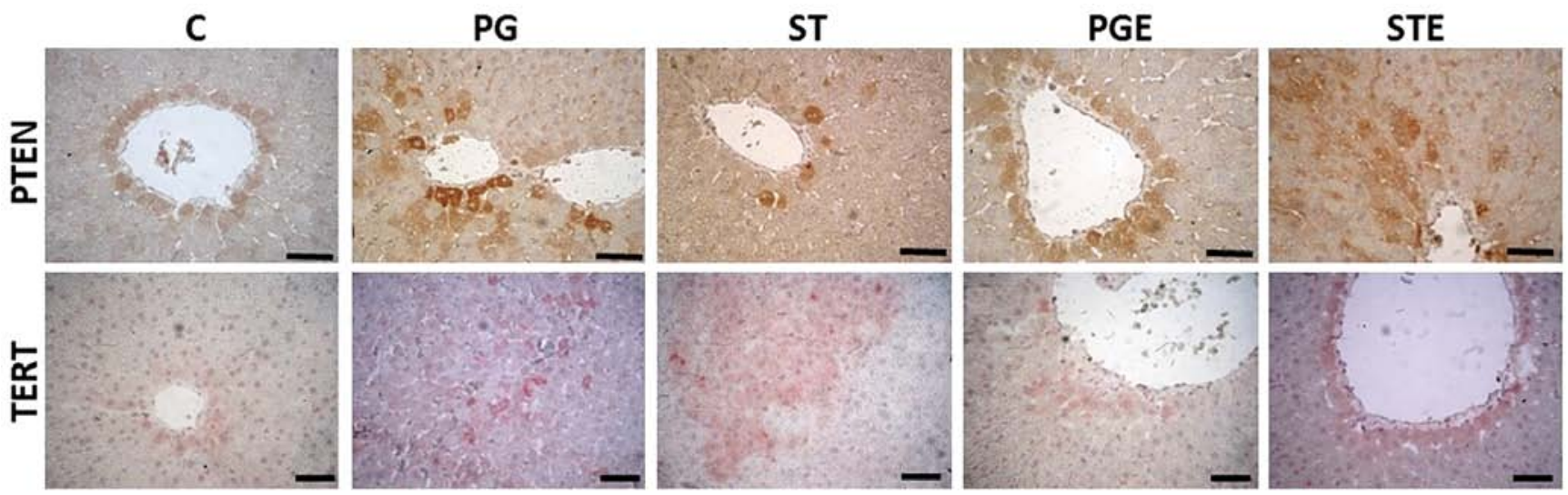

Figure 5. Immunohistochemical staining of PTEN and TERT proteins in all experimental groups (scale bar, $50 \mu \mathrm{m}$ ). The rat groups were as follows: i) The control (C) group; ii) the propylene treatment (PG) group; iii) the stanozolol treatment (ST) group; iv) the propylene treatment and exercise (PGE) group; and v) the stanozolol treatment and exercise (STE) group. PTEN, phosphatase and tensin homolog protein, TERT, telomerase reverse transcriptase.

line with nandrolone, another well-known ASS, which has shown similar effects by increasing telomerase activity in a dose-dependent manner both at the heart tissue and at peripheral blood monocytes $(2,46)$. This may represent a compensating repair mechanism at the tissue level, while increased circulating levels of telomerase activity can depict systemic inflammation. The association of increased telomerase activity and expression with proliferative effects was not likely to occur in this study due to the short time of exposure (28 days). In general, the mechanisms underlying the effects of AASs on telomerase activity have not been elucidated and remain practically unknown.

TERT is a catalytic subunit of a telomerase, which plays a role in its regulation at transcriptional level. It has been reported that TERT mutations are associated with adenoma-carcinoma transitions in the liver (47). Therefore, alterations in TERT regulation and expression play an important role in HCC (48). It has been shown that the tumor suppressor gene, PTEN, negatively correlates with human TERT protein in HCC tissues (21). Therefore, PTEN and TERT play opposing roles in carcinogenesis. It has been reported that PTEN indirectly regulates TERT activity via the PI3K-PKB/Akt pathway in human HCC (21). According to the results of the present study, no significant alterations were observed in PTEN expression levels between the groups. However, TERT gene expression was significantly increased by ST treatment. Exercise reversed the increase in TERT expression induced by stanozolol, particularly in the parenchyma, where metabolic zonation is reported: Glucose release from glycogen and via gluconeogenesis, amino acid utilization and ammonia detoxification, protective metabolism, bile formation and the synthesis of certain plasma proteins, such as albumin and fibrinogen occur mainly in the periportal area, whereas glucose utilization, xenobiotic metabolism and the formation of other plasma proteins, such as alpha 1-antitrypsin or alpha-fetoprotein occur predominantly in the perivenous zone $(49,50)$.

In this study, the levels of 3'-hydroxystanozolol and $16-\beta$-hydroxystanozolol, the main metabolites of stanozolol, were determined in liver tissue samples of stanozolol-treated animals and a dose-response association between telomerase activity and TERT/PTEN gene expressions was determined. The measured levels of 3'-hydroxystanozolol in the ST and
STE groups were associated with the percentage relative telomerase activity, whereas no association was observed for the stanozolol or 16- $\beta$-hydroxystanozolol levels. This may be due to the fact that 3 -hydroxystanozolol is the most potent stanozolol metabolite $(2,51)$.

Several studies have indicated that physical exercise increases telomerase activity in different cell types $(52,53)$. However, to the best of our knowledge, there is no study available to date investigating the effects of stanozolol on telomerase activity in the presence/absence of exercise, apart from our previous study which focused on circlulating telomerase activity in peripheral blood mononuclear cells (PBMCs) (35). Our results indicated the elevation of telomerase activity and TERT expression in the liver tissue, which could be associated either with an increased proliferation risk due to stanozolol treatment (10), rather unlikely for such a short exposure period, or may represent a counteracting mechanism (54). Exercise reverses the stanozolol-induced increase in telomerase activity. A number of studies have supported that exercise exerts hepatoprotective effects. Huang et al demonstrated that a 12-week swimming exercise program suppressed senescence markers and downregulated inflammatory mediators in the liver tissues of D-galactose-induced senescence in rats (55). Yi et al demonstrated that both acute and chronic exercise exerted preventive effects on the livers of rats with type 2 diabetes (56). On the other hand, exercise has been reported to increase liver enzymes in humans (57) and concerns exist regarding the effects of exercise on portal hypertension in patients with cirrhosis (58).

In conclusion, stanozolol induces telomerase activity at a molecular level and exercise reverses this induction, at least regarding TERT expression. This may reflect premature tissue aging due to decreased telomerase activity Future studies are warranted in order to investigate the mechanisms through which exercise can be used to prevent the adverse health effects of stanazolol and to elucidate the molecular hepatocellular mechanisms of the stanozolol-induced adverse effects.

\section{Acknowledgements}

The authors would like to thank Dr Alegakis Athanasios for his valuable help on the statistical advice and comments. 


\section{Funding}

This study was supported by Istanbul University Scientific Research Projects (grant no. 54169-24416).

\section{Availability of data and materials}

The datasets used and/or analyzed during the current study are available from the corresponding author on reasonable request.

\section{Authors' contributions}

EO, MK, AMT, BA and DAS conceived and designed the study, wrote the manuscript and provided valuable suggestions in preparing the manuscript. MK, TK, $\mathrm{PF}$ and MNT performed LC-MS analysis, telomerase activity and gene expression assessments; CT, PDS and DT performed statistical analysis, and data interpretation. EO, MK and BA contributed to the funding application. All authors have read and approved the final manuscript.

\section{Ethics approval and consent to participate}

The animal experiments were approved by the Ethics Committee on Animal Experimentation of Istanbul University, HADYEK (approval no. 2013/100).

\section{Consent for publication}

Not applicable.

\section{Competing interests}

DAS is the Editor-in-Chief of the journal, but had no personal involvement in the reviewing process, or any influence in terms of adjudicating on the final decision, for this article.

\section{References}

1. Balcells G, Matabosch X and Ventura R: Detection of stanozolol $\mathrm{O}$ - and $\mathrm{N}$-sulfate metabolites and their evaluation as additional markers in doping control. Drug Test Anal 9: 1001-1010, 2017.

2. Tsitsimpikou C, Vasilaki F, Tsarouhas K, Fragkiadaki P, Tzardi M, Goutzourelas N, Nepka C, Kalogeraki A, Heretis I, Epitropaki Z, et al: Nephrotoxicity in rabbits after long-term nandrolone decanoate administration. Toxicol Lett 259: 21-27, 2016.

3. World Anti-doping Agency: The 2017 list of prohibited substances and methods. https://www.wada-ama.org/. Accessed Feb 14, 2018.

4. Kioukia-Fougia N, Georgiadis N, Tsarouhas K, Vasilaki F, Fragiadaki P, Meimeti E and Tsitsimpikou C: Synthetic and natural nutritional supplements: Health 'allies' or risks to public health? Recent Pat Inflamm Allergy Drug Discov 10: 72-85, 2017.

5. Tsitsimpikou C, Chrisostomou N, Papalexis P, Tsarouhas K, Tsatsakis A and Jamurtas A: The use of nutritional supplements among recreational athletes in Athens, Greece. Int J Sport Nutr Exerc Metab 21: 377-384, 2011.

6. Sagoe D, Molde H, Andreassen CS, Torsheim T and Pallesen S The global epidemiology of anabolic-androgenic steroid use: A meta-analysis and meta-regression analysis. Ann Epidemiol 24 383-398, 2014.

7. Ampuero J, García ES, Lorenzo MM, Calle R, Ferrero P and Gómez MR: Stanozolol-induced bland cholestasis. Gastroenterol Hepatol 37: 71-72, 2014.

8. Bausserman LL, Saritelli AL and Herbert PN: Effects of short-term stanozolol administration on serum lipoproteins in hepatic lipase deficiency. Metabolism 46: 992-996, 1997.
9. El-Serag HB, Kramer J, Duan Z and Kanwal F: Racial differences in the progression to cirrhosis and hepatocellular carcinoma in HCV-infected veterans. Am J Gastroenterol 109: 1427-1435, 2014.

10. Hansma P, Diaz FJ and Njiwaji C: Fatal liver cyst rupture due to anabolic steroid use: A case presentation. Am J Forensic Med Pathol 37: 21-22, 2016.

11. Harkin KR, Cowan LA, Andrews GA, Basaraba RJ, Fischer JR, DeBowes LJ, Roush JK, Guglielmino ML and Kirk CA: Hepatotoxicity of stanozolol in cats. J Am Vet Med Assoc 217: 681-684, 2000.

12. Socas L, Zumbado M, Pérez-Luzardo O, Ramos A, Pérez C, Hernández JR and Boada LD: Hepatocellular adenomas associated with anabolic androgenic steroid abuse in bodybuilders: A report of two cases and a review of the literature. Br J Sports Med 39: e27, 2005

13. Stimac D, Milić S, Dintinjana RD, Kovac D and Ristić S: Androgenic/anabolic steroid-induced toxic hepatitis. J Clin Gastroenterol 35: 350-352, 2002.

14. Deshmukh NI, Zachar G, Petróczi A, Székely AD, Barker J and Naughton DP: Determination of stanozolol and 3'-hydroxystanozolol in rat hair, urine and serum using liquid chromatography tandem mass spectrometry. Chem Cent J 6: 162, 2012.

15. Mateus-Avois L, Mangin P and Saugy M: Use of ion trap gas chromatography-multiple mass spectrometry for the detection and confirmation of 3'hydroxystanozolol at trace levels in urine for doping control. J Chromatogr B Analyt Technol Biomed Life Sci 816: 193-201, 2005.

16. Kicman AT: Pharmacology of anabolic steroids. Br JPharmacol 154: 502-521, 2008.

17. Büttner A and Thieme D: Side effects of anabolic androgenic steroids: Pathological findings and structure-activity relationships. Handb Exp Pharmacol 195: 459-484, 2010.

18. Rentoukas E, Tsarouhas K, Kaplanis I, Korou E, Nikolaou M, Marathonitis G, Kokkinou S, Haliassos A, Mamalaki A, Kouretas D, et al: Connection between telomerase activity in PBMC and markers of inflammation and endothelial dysfunction in patients with metabolic syndrome. PLoS One 7: e35739, 2012.

19. Kumar M, Lechel A and Güneş Ç: Telomerase: The devil inside. Genes (Basel) 7: E43, 2016.

20. Xu Y and Goldkorn A: Telomere and telomerase therapeutics in cancer. Genes (Basel) 7: E22, 2016.

21. Zhou X, Zhu H and Lu J: PTEN and hTERT gene expression and the correlation with human hepatocellular carcinoma. Pathol Res Pract 211: 316-319, 2015.

22. Wojtyla A, Gladych M and Rubis B: Human telomerase activity regulation. Mol Biol Rep 38: 3339-3349, 2011.

23. Yang C, Li S, Wang M, Chang AK, Liu Y, Zhao F, Xiao L, Han L, Wang D, Li S and Wu H: PTEN suppresses the oncogenic function of AIB1 through decreasing its protein stability via mechanism involving Fbw7 alpha. Mol Cancer 12: 21, 2013.

24. Jung S, Li C, Jeong D, Lee S, Ohk J, Park M, Han S, Duan J, Kim C, Yang Y, et al: Oncogenic function of p34SEI-1 via NEDD4 1 mediated PTEN ubiquitination/degradation and activation of the PI3K/AKT pathway. Int J Oncol 43: 1587-1595, 2013.

25. OECD: Guidance document on the recognition, assessment, and use of clinical signs as humane endpoints for experimental animals used in safety evaluation. OECD, Paris, 2000.

26. Cherici Camargo IC, Barreiros de Souza R, de Fátima Paccola Mesquita S, Chuffa LG and Frei F: Ovarian histology and follicular score in female rats treated with nandrolone decanoate and submitted to physical effort. Acta Biol Hung 60: 253-261, 2009.

27. de Almeida Chuffa LG, de Souza RB, Frei F, de Fátima Paccola Mesquita $S$ and Camargo IC: Nandrolone decanoate and physical effort: Histological and morphometrical assessment in adult rat uterus. Anat Rec (Hoboken) 294: 335-341, 2011.

28. Gopinathan S, O'Neill E, Rodriguez LA, Champ R, Phillips M, Nouraldeen A, Wendt M, Wilson AGE and Kramer JA: In vivo toxicology of excipients commonly employed in drug discovery in rats. J Pharmacol Toxicol Methods 68: 284-295, 2013.

29. Healing G, Sulemann T, Cotton P, Harris J, Hargreaves A, Finney R, Kirk S, Schramm C, Garner C, Pivette P and Burdett L: Safety data on 19 vehicles for use in 1 month oral rodent pre-clinical studies: Administration of hydroxypropyl- $\beta$-cyclodextrin causes renal toxicity. J Appl Toxicol 36: 140-150, 2016.

30. Aye M, Di Giorgio C, De Mo M, Botta A, Perrin J and Courbiere B: Assessment of the genotoxicity of three cryoprotectants used for human oocyte vitrification: Dimethyl sulfoxide, ethylene glycol and propylene glycol. Food Chem Toxicol 48: 1905-1912, 2010. 
31. Berthelot-Ricou A, Perrin J, di Giorgio C, de Meo M, Botta A and Courbiere B: Assessment of 1,2-propanediol (PrOH) genotoxicity on mouse oocytes by comet assay. Fertil Steril 96: 1002-1007, 2011.

32. Cunningham RL and McGinnis MY: Physical provocation of pubertal anabolic androgenic steroid exposed male rats elicits aggression towards females. Horm Behav 50: 410-416, 2006.

33. Matrisciano F, Modafferi AM, Togna GI, Barone Y, Pinna G, Nicoletti $F$ and Scaccianoce S: Repeated anabolic androgenic steroid treatment causes antidepressant-reversible alterations of the hypothalamic-pituitary-adrenal axis, BDNF levels and behavior. Neuropharmacology 58: 1078-1084, 2010.

34. Tucci P, Morgese MG, Colaianna M, Zotti M, Schiavone S, Cuomo V and Trabace L: Neurochemical consequence of steroid abuse: Stanozolol-induced monoaminergic changes. Steroids 77: 269-275, 2012.

35. Kara M, Ozcagli E, Fragkiadaki P, Kotil T, Stivaktakis PD, Spandidos DA, Tsatsakis AM and Alpertunga B: Determination of DNA damage and telomerase activity in stanozolol-treated rats. Exp Ther Med 13: 614-618, 2017.

36. Tsitsimpikou C, Tzatzarakis M, Fragkiadaki P, Kovatsi L, Stivaktakis P, Kalogeraki A, Kouretas D and Tsatsakis AM Histopathological lesions, oxidative stress and genotoxic effects in liver and kidneys following long term exposure of rabbits to diazinon and propoxur. Toxicology 307: 109-114, 2013.

37. Solbach P, Potthoff A, Raatschen HJ, Soudah B, Lehmann U, Schneider A, Gebel MJ, Manns MP and Vogel A: Testosteronereceptor positive hepatocellular carcinoma in a 29-year old bodybuilder with a history of anabolic androgenic steroid abuse: A case report. BMC Gastroenterol 15: 60, 2015.

38. Livak KJ and Schmittgen TD: Analysis of relative gene expression data using real-time quantitative PCR and the 2(-Delta Delta C(T)) Method. Methods 25: 402-408, 2001.

39. Kesler T, Sandhu RS and Krishnamoorthy S: Hepatology: Hepatocellular carcinoma in a young man secondary to androgenic anabolic steroid abuse. J Gastroenterol Hepatol 29: 1852, 2014.

40. Boada LD, Zumbado M, Torres S, López A, Díaz-Chico BN Cabrera JJ and Luzardo OP: Evaluation of acute and chronic hepatotoxic effects exerted by anabolic-androgenic steroid stanozolol in adult male rats. Arch Toxicol 73: 465-472, 1999.

41. Kanayama G, Hudson JI and Pope HG Jr: Long-term psychiatric and medical consequences of anabolic-androgenic steroid abuse: A looming public health concern? Drug Alcohol Depend 98: $1-12,2008$.

42. Ornish D, Lin J, Chan JM, Epel E, Kemp C, Weidner G Marlin R, Frenda SJ, Magbanua MJM, Daubenmier J, et al: Effect of comprehensive lifestyle changes on telomerase activity and telomere length in men with biopsy-proven low-risk prostate cancer: 5-year follow-up of a descriptive pilot study. Lancet Oncol 14: 1112-1120, 2013

43. Mishra S, Kumar R, Malhotra N, Singh N and Dada R: Mild oxidative stress is beneficial for sperm telomere length maintenance. World J Methodol 6: 163-170, 2016.

44. Zar T, Graeber C and Perazella MA: Recognition, treatment, and prevention of propylene glycol toxicity. Semin Dial 20: 217-219, 2007.

45. Djojosubroto MW, Chin AC, Go N, Schaetzlein S, Manns MP, Gryaznov S, Harley CB and Rudolph KL: Telomerase antagonists GRN163 and GRN163L inhibit tumor growth and increase chemosensitivity of human hepatoma. Hepatology 42: 1127-1136, 2005.

46. Vasilaki F, Tsitsimpikou C, Tsarouhas K, Germanakis I, Tzardi M, Kavvalakis M, Ozcagli E, Kouretas D and Tsatsakis AM: Cardiotoxicity in rabbits after long-term nandrolone decanoate administration. Toxicol Lett 241: 143-151, 2016.
47. Pilati C, Letouzé E, Nault JC, Imbeaud S, Boulai A, Calderaro J, Poussin K, Franconi A, Couchy G, Morcrette G, et al: Genomic profiling of hepatocellular adenomas reveals recurrent FRKactivating mutations and the mechanisms of malignant transformation. Cancer Cell 25: 428-441, 2014.

48. Akincilar SC, Unal B and Tergaonkar V: Reactivation of telomerase in cancer. Cell Mol Life Sci 73: 1659-1670, 2016.

49. Jungermann $\mathrm{K}$ and Kietzmann T: Zonation of parenchymal and nonparenchymal metabolism in liver. Annu Rev Nutr 16: 179-203, 1996.

50. Jungermann K: Metabolic zonation of liver parenchyma. Semin Liver Dis 8: 329-341, 1988.

51. Salvador JP, Sánchez-Baeza F and Marco MP: Simultaneous immunochemical detection of stanozolol and the main human metabolite, 3'-hydroxy-stanozolol, in urine and serum samples. Anal Biochem 376: 221-228, 2008

52. Chilton WL, Marques FZ, West J, Kannourakis G, Berzins SP, O'Brien BJ and Charchar FJ: Acute exercise leads to regulation of telomere-associated genes and microRNA expression in immune cells. PLoS One 9: e92088, 2014.

53. Ludlow AT, Gratidão L, Ludlow LW, Spangenburg EE and Roth SM: Acute exercise activates p38 MAPK and increases the expression of telomere-protective genes in cardiac muscle. Exp Physiol 102: 397-410, 2017.

54. Vardavas AI, Stivaktakis PD, Tzatzarakis MN, Fragkiadaki P, Vasilaki F, Tzardi M, Datseri G, Tsiaoussis J, Alegakis AK, Tsitsimpikou C, et al: Long-term exposure to cypermethrin and piperonyl butoxide cause liver and kidney inflammation and induce genotoxicity in New Zealand white male rabbits. Food Chem Toxicol 94: 250-259, 2016.

55. Huang CC, Chiang WD, Huang WC, Huang CY, Hsu MC and Lin WT: Hepatoprotective effects of swimming exercise against D-galactose-induced senescence rat model. Evid Based Complement Alternat Med 2013: 275431, 2013.

56. Yi X, Cao S, Chang B, Zhao D, Gao H, Wan Y, Shi J, Wei W and Guan Y: Effects of acute exercise and chronic exercise on the liver leptin-AMPK-ACC signaling pathway in rats with type 2 diabetes. J Diabetes Res 2013: 946432, 2013.

57. Pettersson J, Hindorf U, Persson P, Bengtsson T, Malmqvist U, Werkström V and Ekelund M: Muscular exercise can cause highly pathological liver function tests in healthy men. Br J Clin Pharmacol 65: 253-259, 2008.

58. Brustia R, Savier E and Scatton O: Physical exercise in cirrhotic patients: Towards prehabilitation on waiting list for liver transplantation. A systematic review and meta-analysis. Clin Res Hepatol Gastroenterol: Nov 18, 2017 (Epub ahead of print).

59. Tapis F: Telomeres are protective caps on the end of chromosomes. Cell, chromosome and DNA vector illustration, Digital image ID: 710795275, Shutterstock. https://www.shutterstock. com/image-illustration/telomeres-protective-caps-on-endchromosomes-735264379.

This work is licensed under a Creative Commons Attribution-NonCommercial-NoDerivatives 4.0 International (CC BY-NC-ND 4.0) License. 